\title{
Intellectual disability-hypoplastic corpus callosum-preauricular tag syndrome
}

INSERM

\section{Source}

INSERM. (1999). Orphanet: an online rare disease and orphan drug data base. Intellectual disability-hypoplastic corpus callosum-preauriculartag syndrome. ORPHA:1495

Intellectual disability-hypoplastic corpus callosum-preauricular tag syndrome is characterised by a hypoplastic corpus callosum, microcephaly, severe intellectual deficit, preauricular skin tags, camptodactyly, growth retardation, and recurrent bronchopneumonia. It has been described in four patients in two families. Transmission is autosomal recessive. 